\title{
Service delivery challenges in Protea Glen, Johannesburg
}

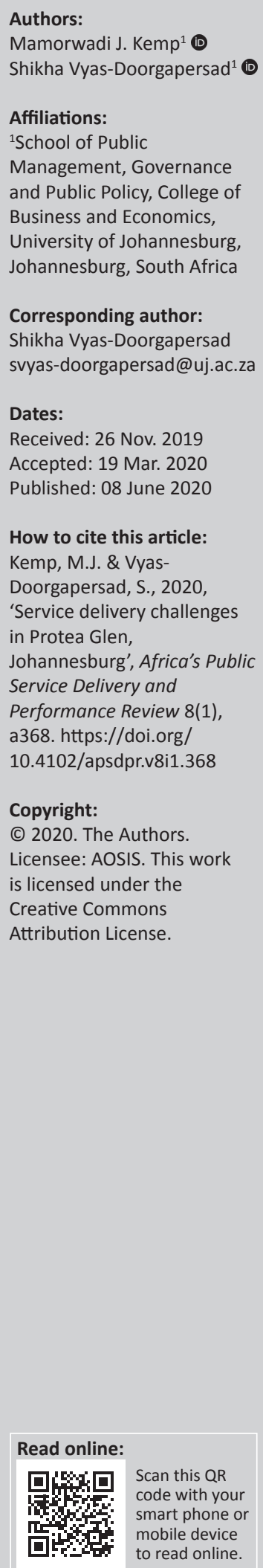

Background: Protea Glen is located in the north of Lenasia and west of Soweto. The face value of Protea Glen is massively disappointing, as the streets are dirty, sewerage pipes are always leaking, rubbish is dumped on every street corner and the streets have potholes and are in a poor condition.

Aim: This article, within the framework of good local governance theory, examines the status of service delivery and institutional measures for improvement in Protea Glen.

Setting: The study is based in Protea Glen, Region D: wards 13 and 135. It falls within the City of Johannesburg Metropolitan Municipality in Gauteng province, South Africa.

Methods: The study adopted a mixed-method data collection approach in conducting the research, which is a combination of qualitative and quantitative research approaches. The data were collected through semi-structured interviews and questionnaire surveys, supplemented with a literature and document review.

Results: The findings revealed several causal factors leading to poor access to water, poor sanitation, inappropriate sewerage services, lack of refuse collection and inadequate electricity services in Protea Glen.

Conclusion: The study proposes recommendations, such as the use of effective technology, educating the community, improving communication and enhancing citizen participation, which all municipalities in general and Protea Glen in particular should take into consideration.

Keywords: good governance; good local governance; Protea Glen; service delivery; South African municipalities; suburbs.

\section{Introduction}

According to Abbas (2017:4, cited in Ncamphalala 2019:1), 'throughout the world, cities are growing at exponential rates'; therefore, $54 \%$ of the world's population [that] was living in urban areas in 2014, is expected to increase to $66 \%$ by 2050' (Ncamphalala 2019:1). As urban municipalities grow, they face the challenge of increased populations, greater service delivery requirements and a more demanding, educated consumer. Many rural municipalities, on the other hand, are shrinking, together with their tax bases and access to capable talent (Ncamphalala 2019:1). The unfulfilled demands of service delivery are also witnessed:

$[O] n$ the African continent, that have experienced and still experience a crisis of political turmoil, intolerance and harsh dictatorship; some countries have a 'military regime' with highly centralised government processes. (Vyas-Doorgapersad 2011:238; Ncamphalala \& Vyas-Doorgapersad 2019:208-209)

The associated problems, as cited by Maseko (2018:29) are:

[S]hortage of qualified staff in district and local government; inadequate standards of training and poor coordination between central, district and local levels of government, all of which hamper effective delivery of services.

This scenario, according to Ncamphalala (2019:5), has impacted negatively the delivery of services to end users who are the consumers of 'municipal services'. Like other African countries, municipalities in South Africa also have to find practical answers to common problems, from providing power, water, homes, roads and transport to catering for the needs of a varying body of citizens (Ncamphalala 2019:6). However, according to the Department of Provincial and Local Government (cited in Vyas-Doorgapersad 2010:47):

$[I] \mathrm{t}$ is an enormous challenge to improve the living conditions of the many communities that are afflicted by unprecedented high levels of unemployment and poverty, historical backlogs in infrastructure services and the uneven spread of economic resources. 
The service delivery challenges affect citizens more in the mini-suburbs of municipalities because of various socioeconomic and institutional challenges. This is an area that is often not well researched. This study aims to examine the status of service delivery in the area of Protea Glen's Region D.

According to the statistics received from Township Realtors (2018), the area of Protea Glen currently comprises approximately 21838 households across all extensions. It also has 500 sectional tittles [townhouses] in Extension 11, bringing the total households of Protea Glen to 22 338. There are also 350 hectares of industrial land approved for development in 2019 between the N12 and Randfontein Road. A further eight extensions (23, 25, 36, 38, 39, 40, 41 and 37) will be built here (Township Realtors 2018). Township Realtors (2018) further highlights that roads and sewerage development is underway, while Eskom is expected to install electricity in the near future. The area will have approximately 8622 households and will bring the total households of Protea Glen to 30960.

When compared to areas of deep Soweto, like Pimville, Meadowlands, Orlando East/West, Diepkloof, Zola, and Jabulani, which are 50 years and older, the standard of living is expected to be better in Protea Glen whereby the houses in the area are mostly bank-financed bond houses, and residents fall under the average working class. Their affordability matches a better standard of living; for instance, they are able to qualify for home loans of between R450 000 and R680 000. This means that their monthly repayment of mortgage bond ranges from R2000 to R6000 per month (Property24 2015). Protea Glen is therefore expected to be a clean and well-managed area. On the contrary, the face value of the area is massively disappointing, as the streets are dirty, sewerage pipes are always leaking, rubbish is dumped on every street corner and the streets have potholes and are in a poor condition. The working class moves to these areas to strive for a better way of living; however, there are serious concerns of poor service delivery. In the past 2 years, there has been an increasing number of community protests by people demanding betterquality service delivery (Protea Urban News 2019). In view of the above background, the main research question that guided this study is as follows: 'what are the variables that hamper the effective and efficient implementation of service delivery in Protea Glen, Region D in particular?' For the purpose of this study, service delivery is considered the unit of analysis. The unit of observation is Protea Glen, Region D, which is also the research setting under study.

Public 'service delivery is associated with the discipline of political science and more specifically, its public administration component' Maseko (2018:27). It was further highlighted by Maseko (2018:27) that:

‘C]lassical and contemporary scholars assert that public administration is an offshoot of political science as a discipline; and as a phenomenon, is as old as humankind itself. The Karl Marxian and Max Weberian schools of thought argue that human beings would cease to exist if the basic public services - such as water and sanitation - were not available to them. This is clearly articulated in Weber's hierarchy of needs'.

It needs to be considered that the paradigm shifts from Public Administration to New Public Management (NPM) also brought various new initiatives for improved delivery of services throughout Africa, including South Africa, 'such as partnerships, corporatisation, privatisation and e-government [as] ground-breaking responses to the pressures of limited municipal resources and the public's insistence that services be improved' (Maseko \& Vyas-Doorgapersad 2018:174). Through NPM, municipalities 'moved to an integrated mode of service delivery where societies are more involved in public service delivery' (Massey \& Johnston-Miller 2016:663). Cavill and Sohail (2004) explain that 'when referring to public service, one refers to services like water and sanitation, street cleaning, solid waste management, roads, community halls and street lights'. In addition, Cavill and Sohail (2004:155) emphasise that:

[M] unicipalities' need to invest in the maintenance, rehabilitation, repair and replacement of equipment used to provide such facilities. These services require adequate resources and this is where good governance is introduced.

\section{Theoretical framework}

This article utilised the good local governance theory. Kartakoullis Karlis, Walker and Locke (2015) elaborate on good governance by stating that 'good governance is about democracy, transparency, and solidarity'. It has the following major characteristics: 'participation, rule of law, transparency, equality, responsiveness, vision, accountability, oversight, efficiency and effectiveness, and professionalism' (VyasDoorgapersad \& Ababio 2010:413-414). These values translate into a broad objective to improve political accountability, participation, an effective rule of law, transparency and flows of information between governments and their citizens (Vyas-Doorgapersad \& Aktan 2017:4). The rationale to adopt this theory is that good governance has a direct impact on service delivery. According to Massey and Johnston-Miller (2016:665), 'the government effectively and efficiently controls public resources and delivers quality public services through good governance practices' and principles. When these practices and principles are applied to municipalities, the notion of good local governance emerges. These principles can improve the status of service delivery and transform local governance into good local governance. According to Lekala (2019:38), ' $[g]$ ood governance makes development possible' and hence fulfils the notion of developmental local governance in South African context. Developmental local governance 'implies a local government that works with various stakeholders, including communities, to establish sustainable ways to improve general socioeconomic wellbeing, and thus improve the quality of living standards' (Lekala 2019:38) through improved delivery of services. Good local governance is also aligned with the vision of the Municipal Structures Act, 1998 (Act 117 of 1998) ensuring that 'municipalities fulfil their constitutional obligations to ensure sustainable, effective and efficient municipal services' (RSA 1998). This theory is used as a theoretical scaffold because of its applicability in the 
South African municipal context as the local government is decentralised and manages the affairs of its governance within the area(s) of jurisdiction. The overall aim of local governance is to offer community members effective and efficient delivery of services.

\section{Service delivery in Protea Glen}

Service delivery, as cited by Maseko (2018:27):

[I]s concerned with the provision of a product or service, by a government or government body to a community that it was promised to, or which is expected by that community.

South African municipalities are facing challenges that hamper service delivery, such as:

$[H]$ uman resource challenges with regards to skills and capacity in municipalities; corruption and maladministration; financial challenges; lack of awareness and lack of knowledge by communities with regards to their rights; and slow rollout of services. (Mdlongwa 2014:39)

In evaluating Protea Glen, Region D, the following challenges were identified as the most crucial ones (City of Johannesburg [CoJ] 2018:133):

$[T]$ here is a high unemployment rate and this challenge is seen to reinforce drugs and alcohol abuse; there is a concern about safety and security; the community requested more clinics to be built in their region and more nurses to be deployed at the clinics that are currently operating in their region. The community also raised the issue of lack of ambulances in their region; there are continuous outages which Eskom takes too long to fix and street lights do not work, with some not working for the past year or so; there is a lack of maintenance of sports facilities; the gravesite fee payable to City Parks is too high and it needs to be re-evaluated; the potholes, water and sanitation as well as traffic lights were also raised as issues that needed urgent attention; lack of economic opportunities; not enough sporting facilities; inadequate budget to meet service delivery requests optimally; there is a high number of thefts on the Uninterrupted Power Supply (UPS), leading to an increase of downtime of traffic signals; some delays in road upgrades due to relocation of existing services; recurrent network challenges leading to system downtime, affecting performance in areas such as pothole repair; and management of interdependencies with other entities.

The CoJ's (2018) annual report indicates that money was spent on critical service delivery areas such as the repair of potholes, however, the photographs in Figures 1-6 raise concerns regarding the standards of service delivery in Protea Glen.

The photographs were taken by the first author of the study. In order to comply with the 'research ethics' aspect of the study, it was ensured by the author that no humans were captured in the photographs.

According to the Johannesburg Road Agency (JRA) website (https://www.jra.org.za/: 2019), 'the JRA aims to repair potholes on major roads and motorways within three working days, and potholes on local roads within five

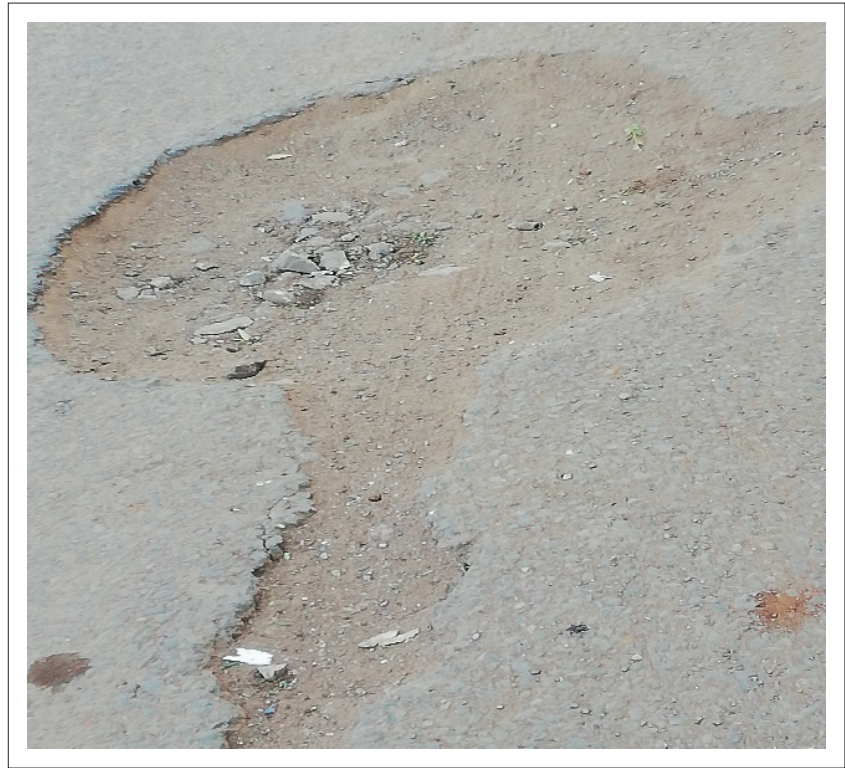

Source: Photo courtesy of Mamorwadi J. Kemp (18 July 2019)

FIGURE 1: Potholes in Extensions 12 in Protea Glen.

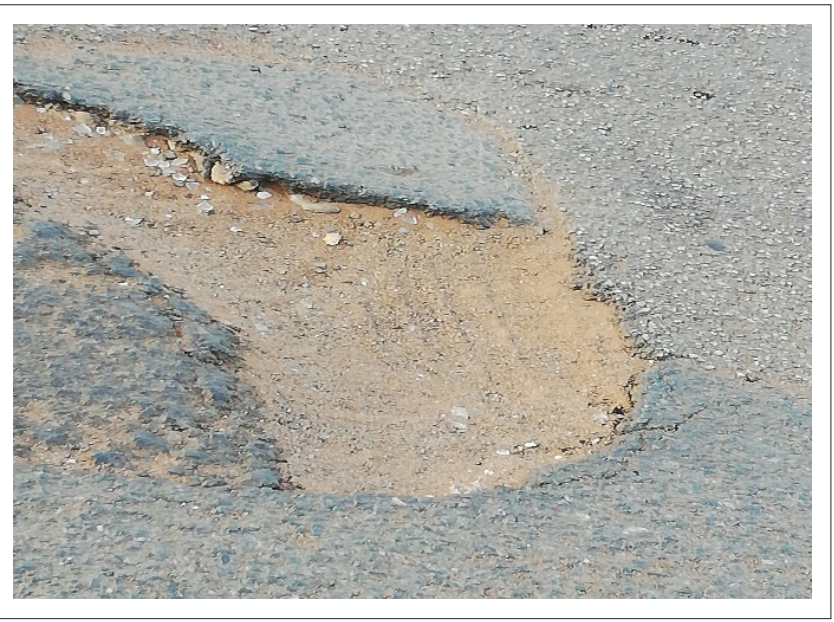

Source: Photo courtesy of Mamorwadi J. Kemp (18 July 2019)

FIGURE 2: Potholes in Extension 13 in Protea Glen.

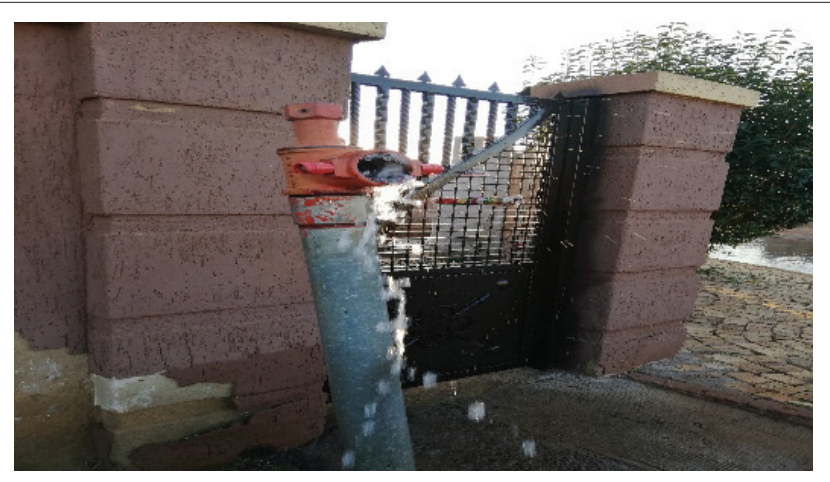

Source: Photo courtesy of Mamorwadi J. Kemp (17 May 2019)

FIGURE 3: Emergency tap leaking in Alabama Street, Extension 16 in Protea Glen.

working days'. The roads in Figures 1 and 2 have, however, been in this condition since 2017, which raises concerns whether this service delivery aspect has been brought to the JRA's attention for improvement. 


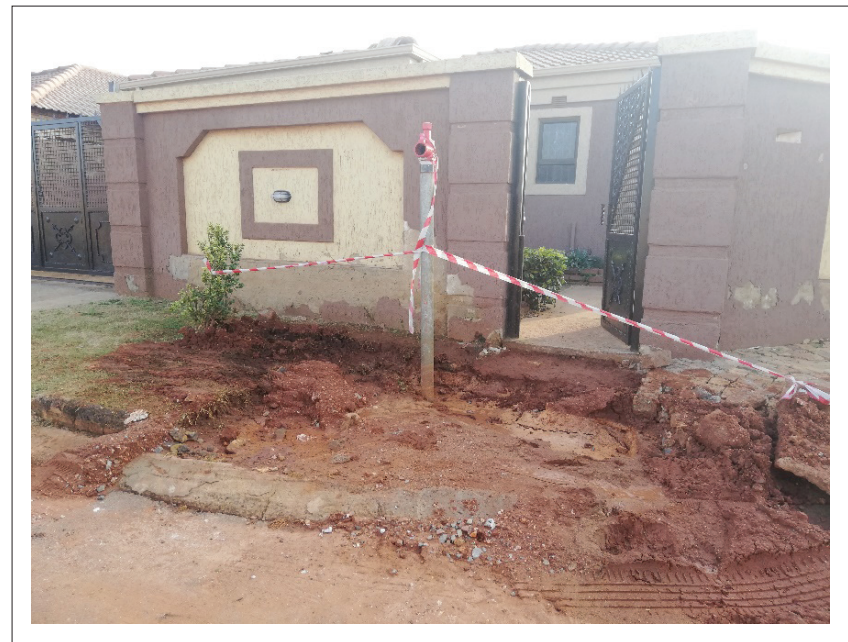

Source: Photo courtesy of Mamorwadi J. Kemp 24 May 2019)

FIGURE 4: Damage caused by the leaking emergency tap in Alabama Street, Extension 16 in Protea Glen.

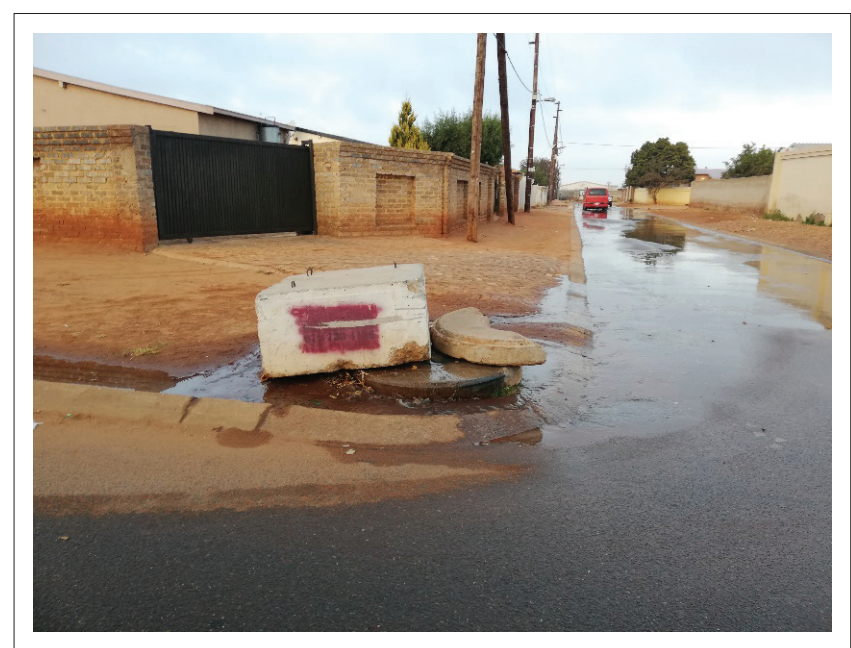

Source: Photo courtesy of Mamorwadi J. Kemp (27 June 2019)

FIGURE 5: Leaking sewerage drain in Alabama Street, Extension 16 in Protea Glen.

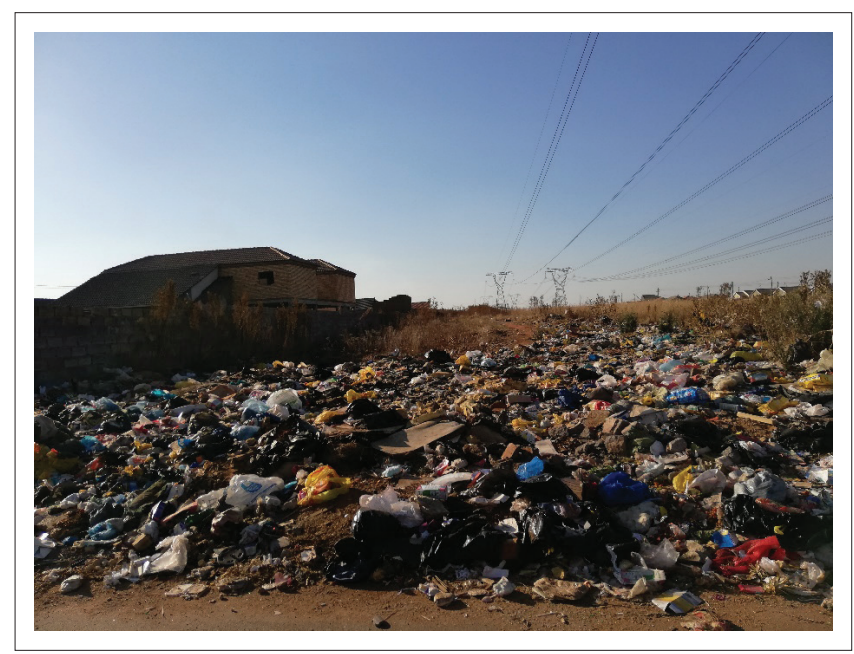

Source: Photo courtesy of Mamorwadi J. Kemp (21 July 2019)

FIGURE 6: Illegal dumping in Protea Glen.

Rand Water took more than $48 \mathrm{~h}$ to respond when the owner of a house in Alabama Street reported a leaking emergency tap. The emergency tap leaked for more than a week after being reported on 17 May 2019. The issue was also reported to the Ward 135 inspector; however, there was still a delay of 3 days before the pipe was attended to. The tap was attended to on 24 May 2019 (the situation was observed by the authors from 17 May 2019).

The response time to leaking sewage is also a concern for Alabama Street residents. There is a sewage drain that leaks regularly in this street; however, nothing has been done to enable a permanent solution. Rand Water employees came and unblocked the drain, but not even a month later it was blocked again (observation by the authors on 24 May 2019).

The CoJ Integrated Development Plan (IDP) Review $2018 / 2019$ confirms that there is neglect and underinvestment in the city's water and sanitation infrastructure, which is a contributing factor to future challenges (CoJ 2019).

The CoJ's (2018) annual report states that Pikitup provides a waste collection service to 858313 formal households on a weekly basis. More than 25000 bins of sizes $240 \mathrm{~L}$ were delivered in the period under review; however, illegal dumping is still a problem in all extensions of Protea Glen.

The CoJ (2018) annual report states that many electricity connections are illegal, and caused by communities that do not have access to electricity. These illegal connections show a rapid increase during the winter season. These challenges can only be addressed by providing communities with access to basic services, such as electricity.

To understand the causes and factors that hamper the effective implementation of service delivery in Protea Glen, the following research methodology was employed to gather data and responses.

\section{Research method}

This study adopted a mixed-method data collection approach, which is a combination of qualitative and quantitative research approaches. Mouton (1996) states that the use of both quantitative and qualitative research methods provides a study with an opportunity to select the best tools from the two methods to obtain valid and reliable data.

The data were collected through semi-structured interviews and survey questionnaires. Interviews:

[A]llow the researcher to pose questions to participants with the aim of learning more about their views, opinions and beliefs. They are also valuable sources of information that allow the researcher to interpret and understand the meanings of the participants' answers to specific questions. (cited in Kotane 2016:46)

Semi-structured interviews were conducted with the Urban Inspector: Citizen Relationship and Urban Management, Integrated Service Delivery, Soweto Region D, in both wards 13 and 135. Only one Urban Inspector deals with service delivery in Protea Glen, Region D; therefore, a total of two urban inspectors formed part of the study from wards 
13 and 135. The purposive sampling approach was utilised to approach the urban inspectors as they are responsible for conducting physical inspections to locate problems and perform walkabouts with relevant stakeholders to address outstanding critical service delivery failures. The interviews were conducted in the Protea North municipal offices located in Ndaba Street, Protea North, Johannesburg.

A survey questionnaire was used to gather data utilising the same set of questions. The 'survey questionnaire is a type of data gathering method that is utilised to collect, analyse and interpret the different views of a group of people from a particular population' (Examples.com 2019). The questionnaires were self-administered, with clear instructions written in English for the majority to understand. Protea Glen has 27 extensions. Only wards 13 and 135 (Region D) were considered for the research. The reason is that the office of the Urban Inspector: Citizen Relationship and Urban Management, Integrated Service Delivery, is situated in these wards, which citizens visit to file complaints regarding service delivery. The researcher used wards 13 and 135 to approach 40 residents (a sample of 20 residents from each ward) to obtain their responses to a semi-structured questionnaire. The convenience sampling method was utilised to approach residents to gather data. The sample size obtained cannot generalise the opinions of all residents of these wards; hence, the study was complemented with secondary literature.

\section{According to Rucker (2017:1):}

$[A]$ lmost all researchers generally like to work with large samples. However, this is not always feasible - especially for students (time, money, resources, etc.) - so it is a good idea to assess need before any real research takes place to determine how many participants are really needed (and can feasibly get) before planning research.

Factors such as insufficient leave from work and financial constraints were some of the reasons for the small sample used in this pilot study.

Quantitative data analysis was used to interpret the questionnaire responses. According to Jarbandhan and Schutte (2006:671), quantitative data refer to the use of variables that can be explained in numbers. It is more concerned with the number of times something occurred'. The researchers (the authors of the present study) used the quantitative approach to collect data from 40 participants. The aim was to gather information about variables that affect service delivery in Protea Glen.

Qualitative data analysis was used to interpret the interview responses. Jarbandhan and Schutte (2006:672) explain qualitative data as the use of data that cannot be explained through numbers. This kind of data are concerned with understanding the setting or the environment in which behaviour occurs. Such data are meant to extract meaning from a situation rather than passing judgement (Jarbandhan \& Schutte 2006). Qualitative data analysis was used in this study to investigate the experience of Urban Bantu Community (UBC) staff members on how local public services are delivered. The researchers approached four staff members (IDP, human resources [HR] and two ward inspectors) working in different sections in the municipal offices. The two inspectors belong to wards 13 and 135 . The researchers were requested not to use their ward numbers in order to not expose their identity. In terms of research ethics, the participants' responses are therefore indicated as Inspector 1 and Inspector 2 in order to safeguard their professional status. The HR personnel was not available; therefore, only the views of the IDP and two ward inspectors are recorded for interpretation.

The interview guide was utilised for guidance. The questions asked were related to the issues of service delivery in Protea Glen, Region D. The respondents were asked the same questions to ensure the validity of the responses. Responses were analysed through thematic analysis where various themes were generated to record the respondents' opinions.

This study conformed to the academic ethics of informed consent, confidentiality, integrity and honesty, and adhered to the non-plagiarism rules. Permission from the management of Protea Glen was obtained to conduct the research in its area of jurisdiction. Consent forms were used, which guaranteed the anonymity and confidentiality of the participants. The study also utilised documents that are available in the public domain.

\section{Ethical consideration}

Ethical clearance was granted by the School of Public Management, Governance and Public Policy, College of Business and Economics, University of Johannesburg (ethical clearance code 2019SPMG12).

\section{Findings, data analysis and interpretation}

The causal factors leading to poor service delivery and institutional measures for improvement in Protea Glen are discussed in the following sub-sections. The responses collected from the interviews and survey questionnaire are incorporated and supplemented with the findings of the literature review.

\section{Status of service delivery in Protea Glen}

This section provides community responses gained from the questionnaire and responses from the interviews conducted with municipal staff members (IDP and inspectors for wards 13 and 135).

\section{Access to water, sewerage and sanitation services}

In the CoJ, Johannesburg Water (JW) is the municipal entity responsible for providing water, sewerage and sanitation services to keep the area clean and healthy. The entity is owned by the $\mathrm{CoJ}$ and is mandated to provide these services to the residents of Johannesburg (JW 2018). 
In the questionnaire, the participants were asked about their satisfaction with the water services in Protea Glen. In Ward 13 , most $(80 \%)$ of the respondents stated that they were not satisfied, and $20 \%$ stated that they were satisfied. The responses provided by the participants in Ward 135 indicated that more than half $(55 \%)$ of the respondents were not satisfied, while $45 \%$ were satisfied. This is a huge difference compared to Ward 13.

The majority of the community members complained about low water pressure during weekends. According to them, the pressure of the water does not seem able to handle the demand during weekends when most community members are at home. Some complained about the cost of water, saying that it is too expensive. Furthermore, the community members indicated that there was no effective prior communication when the water supply would be cut off.

The statistics are supported by responses from municipal employees that indicate that they agreed that the challenges are a matter of concern. Respondent 1 (Inspector 1) and Respondent 2 (Inspector 2) voiced their opinions as follows:

'There are no challenges experienced with Joburg Water as an entity; they attend to reported faults timeously. However, the challenges are experienced with community members who damage pipes and decide to fix them without reporting, which cause more damage because unprofessional people do the job'. (Respondent 1, 2019, male, Inspector 1)

'There is a challenge with damaged infrastructure. However, the municipality started in some areas with the project of replacing damaged infrastructure. Municipalities mostly experience the challenge of limited budget and non-payment'. (Respondent 2, 2019, male, Inspector 2)

The JW's (2018) mid-year report highlights poor sanitation as being responsible for the spread of disease and deaths from infectious diseases. This is linked to the next question in the questionnaire, where the participants were asked to indicate their satisfaction with regard to sewerage services.

In Ward 13, 70\% of the respondents were not satisfied and $30 \%$ were satisfied, while in Ward $135,75 \%$ of the respondents were not satisfied and $25 \%$ were satisfied. These results reflect an overall dissatisfaction in both wards, with only a small percentage indicating satisfaction.

The community members felt that the pipes that were used in building sewerage systems in Protea Glen were too narrow; therefore, there were regular sewage blockages in the area. They felt that this was an unhygienic health hazard to the community.

Respondent 2 referred to damaged infrastructure and limited budget as challenges experienced in offering sewerage services. Respondent 1 raised concerns about community members as follows:

'The community members of Protea Glen throw sanitary pads, wipes, plastics, fat and disposable nappies in their toilets and drains. Hence, there are regular sewage blocks in the area. They need to be educated on the effect of their actions. They need to know that the sewerage infrastructure used is not meant to dissolve unwanted material like wipes, plastics, fat and disposable nappies'. (Respondent 1, 2019, male, Inspector 1)

As a follow-up to sewerage satisfaction, the participants were also asked about their opinions regarding satisfaction with sanitation services. In Ward 13,55\% of the respondents expressed dissatisfaction and $45 \%$ indicated satisfaction. In Ward 135, 20\% of the respondents did not provide responses, $55 \%$ were dissatisfied and 25\% respondents were satisfied.

According to one community member, there are by-laws related to illegal dumping, but those laws are not enforced. The concern is that every open space in Protea Glen is used as a dumping site and authorities are not doing anything to prosecute such people. The area is described as dirty and unhygienic, and land and air pollutions are caused by various factors.

In contrast to the community members' responses, municipal employees agreed that illegal dumping took place but blamed the community members for sanitation challenges. Respondents 1 and 2 mentioned challenges with irresponsible community members who dump rubbish anywhere they see fit without being considerate of other community members.

The community responses are a concern, given that the aims of the JW are to:

$[P]$ rovide all people of Johannesburg with access to quality water and sanitation services. It further aims to deliver a professional, sustainable, affordable and cost-effective service. It wants to develop marginalised areas and create a customer-focused culture by responding to the needs of citizens, customers and business. (JW 2018:5)

The JW's (2018:5) mid-year report states that the:

[E]ntity supplies $1515 \mathrm{ML} /$ day of potable drinking water, procured from Rand Water, through water distribution networks of $12337 \mathrm{~km}, 126$ reservoirs and water towers, and 37 water pump stations. The spent wastewater is then collected and reticulated via $11906 \mathrm{~km}$ of wastewater networks and 39 sewer pump stations. JW treats $841 \mathrm{ML} /$ day of sewerage at its six wastewater treatment works (WWTW), which include two of its biogas-to-energy plants where methane gas is converted to energy.

\section{Access to refuse collection}

The CoJ's (2018) annual report states that Pikitup provides a waste collection service to 858313 formal households on a weekly basis. More than 25000 bins of sizes $240 \mathrm{~L}$ were delivered in the period under review. In order to determine the satisfaction of community members with the service provided by the entity, the researchers asked the participants to indicate their satisfaction. In Ward $13,60 \%$ of the respondents were not satisfied and $40 \%$ were satisfied. In Ward $135,35 \%$ of the respondents were not satisfied, $60 \%$ were satisfied and 5\% respondents did not answer. These results indicate that Ward 13 experienced more challenges 
than Ward 135; however, the fact is that both wards face challenges despite Pikitup's services.

The majority of community members felt that inconsistency in refuse collection and regular employee strikes at Pikitup caused illegal dumping. Some indicated that rubbish bins are stolen during the day when they are at work. To avoid this, they put their rubbish in black plastic bags on collection day and place them outside their gates, but Pikitup employees do not take rubbish in plastic bags. This also causes illegal dumping because household owners end up throwing such rubbish in open spaces. There was also a suggestion from the community members to increase the number of collections to twice a week.

Municipal employees agreed that there was a problem with illegal dumping in the area. Respondent 1 is quoted as saying:

'Open spaces in Protea Glen are cleaned; however, community members do not respect each other's spaces. People dump on open spaces because they know they stay far from the open space and will not be affected by the effects of this action. If community members do not take action on each other's behaviour, illegal dumping will not stop'. (Respondent 1, 2019, male, Inspector 1)

Pikitup reports confirmed that under-performance has been identified, which was significantly influenced by the withdrawal of the service provider contracted by Pikitup to undertake the diversion of green waste. The frequent breakdowns of builders' crusher machines, which lacked maintenance, as well as delayed commencement of the contract for the collection of dry recyclables by contracted service providers, contributed to the problem (CoJ 2018).

\section{Access to electricity}

The entity that provides electricity in the CoJ is Eskom. The CoJ's (2018) annual report indicates that the illegal electricity connections evident in the CoJ are mostly caused by communities who do not have access to electricity or claim that they cannot afford it. This illegal act increases drastically during the winter months of May to July. The only way to address the challenges is by providing communities with access to basic services such as electricity (CoJ 2018).

This is supported by the responses from community members when asked about their satisfaction with electricity services in the questionnaire. In Ward 13, most (95\%) of the respondents were not satisfied, and only $5 \%$ of the respondents said that they were satisfied. In Ward 135, 40\% of the respondents were not satisfied, while $60 \%$ said they were satisfied. Ward 13 was more affected by electricity issues than Ward 135 despite Eskom services.

Community members felt that electricity is too expensive (R100 was equal to 68 units at the time this research was conducted); therefore, the money they pay is not equal to the units they receive. Some community members also felt that there was a lack of maintenance of electricity infrastructure and many houses were connected to one electricity box supply. This results in electricity interruption or boxes being overloaded and exploding. Communication is also a problem when the power supply is cut off without prior warning.

The responses from the municipal employees (respondents 1 and 2) also raised concerns regarding the non-payment of services offered by Eskom. They also mentioned theft of electricity by community members. Respondent 1 is quoted as follows:

'Community members steal street light infrastructure and sell it to the local scrap yards. When the service provider decides to cut electricity due to non-payment, community members protest and vandalise government property'. (Respondent 1, 2019, male, Inspector 1)

The CoJ also acknowledges that it had a high number of high-voltage, medium-voltage and low-voltage outages. The restoration of supply not meeting all NRS047 standards and overloading of the network because of illegal connections were a major concern. Eskom also face issues of ageing infrastructure and network-related incidents. The high number of outages is mainly because of the ageing network, damage by third parties, overloading of the network and vandalism (CoJ 2018).

\section{Institutional measures to improve service delivery in Protea Glen}

This section provides responses from the employees of Protea Glen gained from interviews (municipal employees: IDP and inspectors for wards 13 and 135).

\section{Integrated Development Plan}

According to the CoJ's (2019:12) IDP report, the:

Municipal Systems Act 32 of 2000 requires that municipalities must have a strategic plan. This strategic plan is called an Integrated Development Plan (IDP), which is a five-year plan. It is a social contract between the community and the elected political leadership.

The IDP is the:

[C]ommitment that the leadership makes to the community about how they will meet their needs. This is done through firstly acknowledging challenges facing the municipality and strategising on how to overcome such challenges. It involves extensive planning, consultation, negotiation, implementation and monitoring and evaluation. The community can use the IDP to force the leaders to be accountable on delivering what was planned. (CoJ 2019:12)

Respondent 3 (IDP employee) is quoted as follows:

'The municipality has an IDP policy. Community members are consulted and a list of issues the community would like to see being implemented in their different areas is compiled. It is referred to as a wish list because not everything in the list can and will be addressed due to budget constraints. The list is attended to according to priorities, from the highest to the lowest priority'. (Respondent 3, 2019, male, IDP employee) 
The response above is complemented by the CoJ IDP's aims. In the CoJ's (2019) IDP report, it is stated that it aims to lay the foundation for building a city of opportunity that actively reflects freedom and fairness, and that addresses the issues of poverty and inequality. It also aims to establish an honest and responsive government, one that listens to the people and prioritises their needs. It is tasked with fast-tracking human development and improving the quality of life for CoJ residents. The CoJ, through its IDP, commits to the community of Johannesburg that they will serve them with pride and dignity (CoJ 2019).

\section{Performance management system}

Aguinis (2009) defines performance management as an ongoing process of identifying, measuring and developing the performance of employees and aligning it with the strategic goals of an organisation. Cloete, Rabie and De Coning (2014) refer to performance management as striving towards maximised performance through continuous measurement against clearly defined and agreed-upon standards.

It is unfortunate that even though the three respondents (two inspectors and the IDP employee) confirmed that Performance Management Systems (PMSs) have been implemented by the HR division, they could not provide detailed information on how they are implemented. The respondents indicated that PMS is an HR function and only HR personnel can provide such information. The HR personnel was not available for an interview for this study.

Information gathered from $\mathrm{CoJ}$ employees indicates that the CoJ has developed a Group Performance Management Policy to measure the actual delivery compared with planned goals and strategic objectives. The CoJ uses a PMS that conforms to key legislative and regulatory requirements. It ensures that its PMS is an appropriate mechanism through which the performance of the $\mathrm{CoJ}$ at all levels can be coordinated, integrated and optimised to achieve the fundamental goals of the organisation (CoJ 2012b).

\section{Capacity building}

According to the United Nations Development Programme (UNDP 2009), capacity building means different things to different people. In one context, it can be viewed as an effort to teach someone to do something better. It may also mean building a new institution or strengthening existing institutions, and it can also concentrate on education and training.

The CoJ's (2018) annual report states that the Skills Development Act (No. 97 of 1998) requires that public officials should be capacitated according to the provisions of this Act. The CoJ ensured that a number of employees were trained in their specific job requirements in order to enable them to function at the optimum level. Management staff members at all levels were trained in leadership and management skills (CoJ 2018).

The three respondents (two inspectors and one IDP employee) were, however, not in agreement regarding the availability of capacity-building initiatives to equip personnel to offer effective and efficient service delivery. Respondent 1 (Inspector 1) stated that there were no capacity-building initiatives. Respondent 2 (Inspector 2) said that there were capacity-building initiatives, and Respondent 3 (IDP employee) could not provide further information on the matter. The researchers were referred to the HR department for further information, but the HR personnel was not available for an interview.

In support of the above responses, the CoJ's (2018) annual report indicates that financial constraints are an obstacle in meeting all employee capacitation requirements. The CoJ therefore had to prioritise and focus on the most urgent training needs. This means that not all employees were accommodated; hence, the above employees were not aware of the initiatives. In light of these financial constraints, the $\mathrm{CoJ}$ is considering building internal capacity in order to reduce over-reliance on service providers (CoJ 2018).

\section{Citizen participation platforms}

Section 195(1)(e) of the Constitution states that people's needs must be responded to. In section (f), it is further stated that public administration must be accountable. This can only be achieved with citizen-government partnership, where citizens and the government work together to satisfy the needs of the community (RSA 1996).

The three respondents (inspectors 1 and 2 and the IDP employee) confirmed that Protea Glen has citizen participation forums. Respondent 2 indicated that there are street committees and community policing forums, while Respondent 3 referred to them as community committees. Respondent 2 was vocal about citizen participation, which is evident in the following quote:

'The counsellor's office calls community meetings to discuss issues affecting community members. There is also a community WhatsApp group, which area inspectors are members of. The group is used to report service delivery issues or complain and the inspector makes a follow-up of such complaints. The region also calls community meetings for discussions on matters involving the community. The participation of community members in improving service delivery is poor and they damage children's parks with dumping rubble there'. (Respondent 2, 2019, male, Inspector 2)

According to the CoJ's (2018:54) annual report:

[T]he politically elected ward councillors work together with ward committees. The committees constitute public representatives elected by community members. These committees intend to enhance participatory democracy in local government by assisting ward councillors in carrying out their mandate. Their aim is to boost the participation of the public in the affairs of Council.

The report further indicates that the public can 'also advise and make recommendations to ward councillors on matters that are affecting the ward' [and]: 
$[M]$ eetings are held monthly to discuss issues raised within the community and to obtain feedback from the ward councillor on significant issues and decisions reached at council. Such committees do not seem to exist in Protea Glen and therefore no monthly meetings are held. (CoJ 2018:54)

\section{Human resource measures to appoint skilled and competent staff}

Human resources refer to the people. The roles of the HR department, amongst others, include conducting job analyses, planning personnel needs and recruiting skilled people for the job (Parameswari \& Yugandhar 2015:58).

Respondents 1 and 2 stated that they did not have an idea about the HR processes and referred the researchers to the HR department. Respondent 3 confirmed that the HR department has measures in place to appoint skilled and competent staff through the recruitment process adopted, and hence also referred the researchers to the HR department for further information on the matter, but as stated previously, the HR personnel was not available for an interview.

The CoJ's (2018) annual report confirms the existence of proper recruitment procedures by stating that in order to provide the residents of $\mathrm{CoJ}$ with professional, effective and efficient service delivery, the CoJ must ensure that it employs people with the required skills, experience and ability. The CoJ's recruitment process is supported by human capital management programmes and projects. It is through these programmes and projects that the human capital capacity of the $\mathrm{CoJ}$ is constantly assessed and developed to adapt to a changing environment. It further ensures that employees possess the required skills and competencies to deliver the required services (CoJ 2018).

\section{Monitoring \& evaluation}

According to Kariuki and Reddy (2017), monitoring \& evaluation (M\&E):

$[A]$ re complementary activities. While monitoring is a routine activity that assesses an intervention's progress towards the realisation of its goals, evaluation is an in-depth assessment of its value that seeks to determine the reasons for the observable effects of a programme. Therefore, monitoring and evaluation reinforce each other. (p. 3)

As cited by Kariuki and Reddy (2017:3), M\&E systems 'are used to provide information that enables the promotion of good governance and accountability in government'.

Respondents 1 and 2 confirmed that systems were used by ward inspectors and the service-level agreement (SLA) team to monitor and evaluate service delivery issues. Respondent 2 is quoted as follows:

'The inspector identifies faults within the area they are dedicated to. He then reports it using the sub-system which has an SLA on when the fault must be attended. The inspector needs to go back to the area after the time lapse to see if the fault was attended to. Inspectors submit weekly reports on all faults reported to the SLA team for further investigation'. (Respondent 2, 2019, male, Inspector 2)
According to the CoJ's M\&E Framework, it aims to improve M\&E within all municipal entities and internal departments. The document provides common understanding of key M\&E principles and elements amongst role-players in the city. The CoJ, through this framework, aims to share information about $\mathrm{M} \& \mathrm{E}$, have a standardised language and approach in applying $\mathrm{M} \& \mathrm{E}$, improve its practices, clarify the roles and responsibilities of M\&E activities and, lastly, ensure transparency and accountability in using M\&E information (CoJ 2012a).

\section{Recommendations}

The main findings of the study indicate that a great deal of work must be conducted to strengthen the relationship between the government and community members. This can only be achieved by implementing good governance in municipal administration.

The study highlights that there are by-laws that exist on paper but that there is a lack of implementation of such laws; however, if these laws are not enforced, people will do as they please and communities will not have order and discipline. For instance, Protea Glen is dirty because there is no enforcement to fine or arrest community members who commit such acts, for example, illegal dumping.

Not paying for services was also identified as a huge dissatisfaction amongst community members and government employees. There is a huge demand for service delivery; however, the income received by the government is low. In the same breath, communities expect consistent and uninterrupted service delivery. When the government fails to provide services, communities start protesting and damaging property.

Several issues were raised by the community members and municipal employees. After the analysis of the data on the prospects of service delivery collected through interviews and questionnaires, this study proposes the following recommendations that $\mathrm{CoJ}$ in general, and Protea Glen in particular, should take into consideration towards attaining effective and efficient service delivery as the fundamental outcome of local government.

\section{The use of effective technology for billing systems}

The community members who participated in answering the questionnaire raised concerns with the cost of water and electricity. According to them, the municipality is not fair regarding billing the community. Therefore, Protea Glen needs a proper and fair billing system for community members to be satisfied.

\section{Educate the community}

The community members are responsible for the damage to some of the infrastructure in their communities. They need to be educated on how to maintain the resources at their disposal and stop waiting for the government to do things 
for them. Protea Glen needs to organise education awareness programmes aimed at educating citizens on how to take care of their environment to keep it clean and safe.

Education programmes must include education on recycling. Protea Glen needs to find ways to teach citizens how to use waste to create useful materials to benefit their communities. For instance, the rubble that people throw away after extending their houses can be used to create bricks. Plastics can be used to make beautiful caps and household carpets. Community members can be educated on purifying their own water for reuse and thereby saving this scarce resource. It is important to educate the community members about the importance and benefits of living in a clean area.

\section{Improve communication}

Several of the participants' responses revealed that there is a lack of communication. Lack of communication affects service delivery and attendance of important community meetings called by municipalities and their counsellors. State-led smart governance initiatives would solve this issue of poor communication as it is clear that the current form of communication is not reaching all community members.

\section{Improve citizen participation forums}

In the interviews conducted with municipal employees, the criticism was mainly about the poor participation of citizens in meetings called by counsellors of the region or the area. The citizens need to start realising that public service delivery is based on good governance, which requires their participation in decision-making processes. There is therefore a great need for citizens to fully participate in government processes. In order for the government to render the required relevant services to the people, the citizens themselves must indicate what their needs are.

\section{Conclusion}

City of Johannesburg and Protea Glen may use digitalised and Fourth Industrial Revolution (4IR) initiatives to improve the situation, for example, the use of biomimicry. According to Biomimicry Institute (2019:1), biomimicry:

$[I] \mathrm{s}$ an approach to innovation that seeks sustainable solutions to human challenges. It emulates nature's time-tested patterns and strategies. The goal is to create new ways of living using nature. Its use in communities might be helpful in saving government costs on most services.

The use of such innovations, however, also requires adequate infrastructure, citizen awareness, community garden spaces, equipment and electricity, to name a few. This may be an area of further research. The study could also possibly be extended to embrace a detailed investigation in which the following area can be explored: 'The role of ICT/4IR for improved service delivery in Protea Glen'. The nature of such advanced research would result in a better impact assessment of the role of digitalised innovations that resonate with the 4IR for improved service delivery in South African municipalities.
In conclusion, it is significant for all municipalities in general and Protea Glen in particular to conduct continuous M\&E of service delivery standards in order to identify weaknesses and to find solutions for improvement.

\section{Acknowledgements}

The authors acknowledge the works of scholars who have contributed their knowledge, debating the aspects of service delivery in South Africa. This article is based on a completed Master mini-dissertation of the first author (M.J.K.), titled 'Variables influencing service delivery in Protea Glen, Johannesburg', at University of Johannesburg under the supervision of Prof. S. Vyas-Doorgapersad.

\section{Competing interests}

The authors declare that they have no financial or personal relationships that may have inappropriately influenced them in writing this article.

\section{Author's contributions}

Both authors contributed equally to this work.

\section{Funding information}

This study received no specific grant from any funding agency in the public, commercial or not-for-profit sectors.

\section{Data availability statement}

Data sharing is not applicable to this article as no new data were created or analysed in this study.

\section{Disclaimer}

The views and opinions expressed in this article are those of the authors and do not necessarily reflect the official policy or position of any affiliated agency of the authors.

\section{References}

Abbas, R.A., 2017, 'A comparison of smart city indicators in for three top ten US Cities', Unpublished MA Dissertation, University of Texas, Arlington, TX.

Aguinis, H., 2009, Performance management, Prentice Hall, Upper Saddle River, NJ.

Biomimicry Institute, 2019, Biomimicry 101: What is Biomimicry? viewed 14 May 2019, from https://biomimicry.org/what-is-biomimicry/.

Cavill, S. \& Sohail, M., 2004, 'Strengthening accountability for urban services', Environment \& Urbanization 16(1), 155-170. https://doi.org/10.1630/095624704323026223

City of Johannesburg (CoJ), 2012a, City of Johannesburg's monitoring and evaluation framework, viewed 18 August 2019, from http://www.statssa.gov.za/publications/ P0318/ P03182017.pdf.

City of Johannesburg (CoJ), 2012b, Group Performance Management Policy (GPMP) viewed 15 August 2019, from https://www.joburg.org.za/documents / Documents/ Policies $\% 20$ Blayi/Group $\% 20$ Corporate $\% 20 \% \mathrm{EF} \% \mathrm{BC} \% 8$.

City of Johannesburg (CoJ), 2018, City of Johannesburg annual report 2017/18, viewed 13 August 2019, from https://www.joburg.org.za/documents/Documents/ Annual\%20Reports/ 20172018/CoJ\%20Annual\%20Report\%202017-18\%20_4\%20 March\%202019.pdf.

City of Johannesburg (CoJ), 2019, City of Johannesburg Draft Integrated Development Plan (IDP) review 2018/19, viewed 19 August 2019, from https://www.joburg.org. $\mathrm{za} /$ documents /Documents/Intergrated\%20Development $\% 20 \mathrm{Plan} / \mathrm{idp} \% 20$ documents/IDP\%20for\%20Council\%20(2).pdf.

Cloete, F., Rabie, B. \& De Coning, C., 2014, Evaluation management in South Africa and Africa, Sun Press, Stellenbosch.

Examples.com, 2019, Survey questionnaire, viewed 12 September 2019, from https:// www.examples.com/education/what-is-a-survey-questionnaire.html. 
Jarbandhan, D.B. \& Schutte, D.W., 2006, 'Using the survey procedure and interview data collection technique', Journal of Public Administration 41(3.1), 669-681.

Johannesburg Road Agency (JRA), 2019, Regional map, viewed 15 September 2019, from https://www.jra.org.za/jra-info/regional-map.

Johannesburg Water (JW), 2018, Mid-year report, 2017/18, viewed 15 Septembe 2019, from www.johannesburgwater.co.za.

Kariuki, P. \& Reddy, P., 2017, 'Operationalising an effective monitoring and evaluation system for local government: Considerations for best practice', African Evaluation Journal 5(2), a240. https://doi.org/10.4102/aej.v5i2.240

Kartakoullis, N., Karlis, G., Walker, T. \& Locke, M.C., 2015, 'Good governance and management practices: The perspectives of Cyprus National Sport Federations administrators', International Journal of Sport Management, Recreation \& Tourism 19(d), 62-74. https://doi.org/10.5199/ijsmart-1791-874X-19d

Kotane, J.M., 2016, Public service delivery in the Gauteng Province: The case of housing development in Braamfischerville, Soweto, South Africa, University of South Africa, Pretoria.

Lekala, E., 2019, 'Investigating good local governance for developmental local government: The case of Prince Albert Municipality', Unpublished MA dissertation Stellenbosch University, Stellenbosch.

Maseko, N., 2018, 'Alternative service delivery mechanisms within the City of Johannesburg Metropolitan Municipality', Unpublished MA dissertation, University of Johannesburg, Johannesburg.

Maseko, N. \& Vyas-Doorgapersad, S., 2018, 'Alternative service delivery mechanism within the City of Johannesburg Metropolitan Municipality', Administratio Publica 26(3), 170-190.

Massey, A. \& Johnson-Miller, K., 2016, 'Governance: Public governance to social innovation?', Policy \& Politics 44(4), 663-675. https://doi.org/10.1332/03055731 4X14042230109592

Mdlongwa, E.T., 2014, Local government at the heart of poor service delivery, viewed 13 August 2019, from http://psam.org.za/research/1460540011.pdf.

Mouton, J., 1996, Understanding social research, Van Schaik Publishers, Pretoria.

Ncamphalala, M., 2019, 'The role of ICT to promote smart governance in local governments', Unpublished MA dissertation, University of Johannesburg, Johannesburg.
Ncamphalala, M. \& Vyas-Doorgapersad, S., 2019, 'The use of ICT for smart governance in the City of Ekurhuleni', Administratio Publica 27(3), 205-221.

Parameswari, B.N. \& Yugandhar, V., 2015, 'The role of human resource management in organizations', International Journal of Engineering Technology, Management and Applied Science 3(7), 58-63.

Property24, 2015, New developments for Soweto's Protea Glen. 27/03/2015, viewed 23 May 2019, from https://www.property24.com/articles/new-development-forsowetos-Protea Glen/21725.

Protea Urban News, 2019, Service delivery protests in Protea Glen, Caxton Urban Community Newspaper, Soweto, 18 February, 2019, n.p.

Republic of South Africa (RSA), 1996, The Constitution of the Republic of South Africa, 1996, Government Printer, Pretoria.

Republic of South Africa (RSA), 1998, Municipal Structures Act, 117 of 1998, Government Printer, Pretoria.

Rucker, M., 2017, How to determine the sample size for your study, viewed 27 September 2019, from https://unstick.me/determine-the-sample-size-study/.

Township Realtors, 2018, Township Realtors (SA) (Pty) Ltd, viewed 08 June 2019, from https://www.africanadvice.com/1408537/Property_Companies_And Developers/Roodepoort/Township_Realtors_(sa)_(PTY)_Ltd/.

Unite Nations Development Programme (UNDP), 2009, Capacity development: A UNDP primer, viewed 13 May 2019, from http://www.undp.org/capacity.

Vyas-Doorgapersad, S., 2010, 'Capacity-building for developmental local governance in South Africa', Journal of Public Administration 45(1), 43-57.

Vyas-Doorgapersad, S., 2011, 'Paradigm shift from new public administration to new public management: Theory and practice in Africa', TD: The Journal for Transdisciplinary Research in Southern Africa 7(2), 235-250. https://doi.org/ 10.4102/td.v7i2.240

Vyas-Doorgapersad, S. \& Ababio, E.P., 2010, 'The illusion of ethics for good local governance in South Africa', TD: The Journal of Transdisciplinary Research in Southern Africa 6(2), 411-427. https://doi.org/10.4102/td.v6i2.273

Vyas-Doorgapersad, S. \& Aktan, C.C., 2017, 'Progression from ideal state to good governance: An introductory overview', International Journal of Business and Management Studies 9(1), 29-49. 